\title{
Electrochromic properties of nanostructured tungsten trioxide (hydrate) films and their applications in a complementary electrochromic device
}

\author{
Zhihui Jiao a, Jinmin Wanga ${ }^{a}$, Lin Ke ${ }^{b}$, Xuewei Liuc ${ }^{c}$, Hilmi Volkan Demir ${ }^{\text {a,d,e }}$, Ming Fei Yang ${ }^{a}$, \\ Xiao Wei Sun ${ }^{\mathrm{a}, \mathrm{f}, *}$ \\ a School of Electrical and Electronic Engineering, Nanyang Technological University, Nanyang Avenue, Singapore 639798, Singapore \\ ${ }^{\mathrm{b}}$ Institute of Material Research and Engineering, A*STAR (Agency for Science, Technology and Research), Research Link, Singapore 117602, Singapore \\ ' School of Physical and Mathematical Sciences, Nanyang Technological University, Nanyang Avenue, Singapore 637371, Singapore

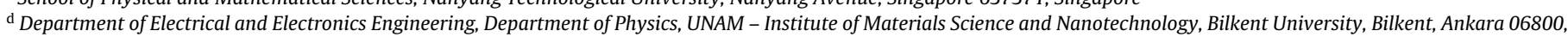 \\ Turkey \\ e School of Physical and Mathematical Sciences, Nanyang Technological University, Nanyang Avenue, Singapore 639798, Singapore

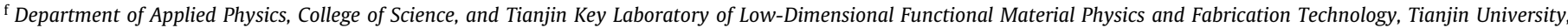 \\ Tianjin 300072, China
}

\section{A R T I C L E I N F O}

\section{Article history:}

Received 31 August 2011

Received in revised form

16 December 2011

Accepted 18 December 2011

Available online 26 December 2011

\section{Keywords:}

Electrochromism

Tungsten trioxide

Thin film

Complementary device

\begin{abstract}
A B S T R A C T
Orthorhombic hydrated tungsten trioxide $\left(3 \mathrm{WO}_{3} \cdot \mathrm{H}_{2} \mathrm{O}\right)$ films consisted of nanosticks and nanoparticles were prepared on fluorine doped tin oxide (FTO)-coated substrate by a facile and template-free hydrothermal method using ammonium acetate $\left(\mathrm{CH}_{3} \mathrm{COONH}_{4}\right)$ as the capping agent. Irregular nanobrick films were obtained without capping agent. Due to the highly rough surface, the nanostick/nanoparticle film depicts faster ion intercalation/deintercalation kinetics and a greater coloration efficiency $\left(45.5 \mathrm{~cm}^{2} / \mathrm{C}\right)$ than the nanobrick film. A complementary electrochromic device based on the nanostick/nanoparticle $3 \mathrm{WO}_{3} \cdot \mathrm{H}_{2} \mathrm{O}$ film and Prussian blue (PB) was assembled. As a result, the complementary device shows a higher optical modulation ( $54 \%$ at $754 \mathrm{~nm})$, a larger coloration efficiency $\left(151.9 \mathrm{~cm}^{2} / \mathrm{C}\right)$ and faster switching responses with a bleaching time of $5.7 \mathrm{~s}$ and a coloring time of $1.3 \mathrm{~s}$ than a single $3 \mathrm{WO}_{3} \cdot \mathrm{H}_{2} \mathrm{O}$ layer device, making it attractive for a practical application.
\end{abstract}

(C) 2011 Elsevier Ltd. All rights reserved.

\section{Introduction}

Upon electron-transfer or redox reactions, materials that undergo reversible color changes with variations in their optical spectra are called electrochromic materials [1-3]. Electrochromic devices composed of these materials, which allow for controlling color cycles, have attracted great interest thanks to their applications important for smart windows [4-6], displays $[7,8]$ and antiglare mirrors [9]. The tunable light transmittance resulting from the color change of the electrochromic films is much desired in smart windows, which do not only increase the aesthetics of traditional windows but also save energy by reducing heating or cooling loads of the building interiors [10]. Among various electrochromic materials, tungsten oxide $\left(\mathrm{WO}_{3}\right)$ has been extensively studied because of its high coloration efficiency and high cyclic stability compared with other transition metal oxides [11].

\footnotetext{
* Corresponding author at: School of Electrical and Electronic Engineering, Nanyang Technological University, Nanyang Avenue, Singapore 639798, Singapore. Tel.: +65 67905369; fax: +65 67933318.

E-mail address: exwsun@ntu.edu.sg (X.W.Sun).
}

Moreover, $\mathrm{WO}_{3}$-based electrochromic devices exhibit low power consumption, a good memory effect and a high contrast ratio [12], offering the desired advantages in smart windows and displays. It is widely recognized that nanostructured $\mathrm{WO}_{3}$, in comparison to their compact bulk forms, offer potential advantages in electrochromic application due to their large surface area that could both increase the contact area between the electrode and electrolyte and reduce the diffusion path of ions through the porous structures [13]. And the electrochromic efficiency of $\mathrm{WO}_{3}$ can be further improved by doping suitable metal ions with higher electronegativity or lower oxidizing capability than $\mathrm{W}$ ions, such as Mo and Ti $[14,15]$. Recently, one-dimensional (1D) $\mathrm{WO}_{3}$ nanostructures with large surface areas, including nanowires [16,17], nanorods [18,19] and nanobelts [20], have been investigated. For electrochromic applications, $\mathrm{WO}_{3}$ nanostructures need to be assembled as a thin film on conductive substrates and the microstructures of the film concerning the electrochromic performance largely depend on the film assembling techniques and processing conditions. Such thin films of $\mathrm{WO}_{3}$ have been grown by vacuum deposition [21], electrodeposition [22], sol-gel [23] and hydrothermal method [24,25]. Hydrothermal approach is one of the most promising methods for fabricating $\mathrm{WO}_{3}$ film because of its merits of low cost, low 
reaction temperature, flexible substrate selection and easy scalingup for production. Moreover, the microstructures of $\mathrm{WO}_{3}$ films grown by hydrothermal approach can be precisely tailored by varying the precursor concentration, temperature, duration, and adopting various surfactants and capping agents.

To date, a number of hydrothermal methods have been developed for preparing $1 \mathrm{D} \mathrm{WO}_{3}$ nanostructures, including nanorods [19] and nanoribbons [26] by adding different inorganic salts as capping agents. However, previous reports of directly grown $\mathrm{WO}_{3}$ thin films on substrate using a template-free hydrothermal process and their corresponding electrochromic characteristics have been quite limited. For example, Tu's group reports a hydrothermally grown $\mathrm{WO}_{3}$ nanowire arrays film recently [27]. A high coloration efficiency of $102.8 \mathrm{~cm}^{2} / \mathrm{C}$ and fast switching response of $4.2 \mathrm{~s}$ for coloration and $7.6 \mathrm{~s}$ for bleaching is achieved for this film. Our group has also fabricated nanobrick $\mathrm{WO}_{3}$ film on transparent conductive substrate using a crystal-seed-assisted hydrothermal method previously [24]. The film shows a good cyclic stability and comparable coloration efficiency $\left(38.2 \mathrm{~cm}^{2} / \mathrm{C}\right)$. Although considerable achievements have been made, the electrochromic properties of hydrothermally grown nanostructured $\mathrm{WO}_{3}$ films can be further improved by increasing their surface area. Moreover, the capping agent effects on the morphology of the hydrothermally grown $\mathrm{WO}_{3}$ films and their resultant electrochromic characteristics have not been totally understood yet.

Compared with a single layer electrochromic device, it is well known that a complementary device containing two proper electrochromic layers could further improve the performance, such as the optical modulation, cyclic stability and coloration efficiency $[28,29]$. Prussian blue (PB, iron (III) [hexacyanoferrate (II)]), a coordination-compounded transition metal hexacyanometallate, is a suitable complementary electrochromic material to $\mathrm{WO}_{3}$ due to its outstanding electrochromic performance and proper operational voltage range. Although complementary electrochromic devices with improved properties based on electrodeposited $\mathrm{WO}_{3}$ and PB films have been reported [30], to the best of our knowledge, little work has been done on applying the hydrothermally grown nanostructured hydrated tungsten oxide films in such kind of devices.

In this work, we make an attempt to grow nanostructured $\mathrm{WO}_{3}$ films directly on FTO-coated glass by a hydrothermal method using ammonium acetate $\left(\mathrm{CH}_{3} \mathrm{COONH}_{4}\right)$ as the capping agent. The capping effects of $\mathrm{CH}_{3} \mathrm{COONH}_{4}$ on the structure, morphology and electrochromic property of the resulting nanostructured hydrated tungsten oxide films are investigated. Moreover, a complementary electrochromic device combining the hydrated tungsten oxide film with PB film is fabricated and, as a result, increased optical modulation and coloration efficiency is demonstrated.

\section{Experimental}

\subsection{Preparation of crystal seed layers, precursor and hydrothermal treatment}

The detailed procedures for preparing crystal seed layers can be found elsewhere [24]. In a typical experiment for preparing the precursor, $\mathrm{Na}_{2} \mathrm{WO}_{4} \cdot 2 \mathrm{H}_{2} \mathrm{O}(0.0655 \mathrm{~g})$ was dissolved into $20 \mathrm{~mL}$ of de-ionized water and then $4 \mathrm{~mL}$ of $\mathrm{HCl}$ was added into the solution until no more precipitate was formed. The above suspension was kept in ice bath for about $10 \mathrm{~min}$, then the top liquid part was removed and de-ionized water was added to obtain a $20 \mathrm{~mL}$ suspension. Subsequently $\mathrm{H}_{2} \mathrm{O}_{2}(0.2 \mathrm{~g})$ was added into the above suspension under intensely stirring and heating. The white precipitate was dissolved and a transparent solution was obtained. After stirring for $5 \mathrm{~min}, \mathrm{CH}_{3} \mathrm{COONH}_{4}(0.1 \mathrm{~g})$ was added as the capping

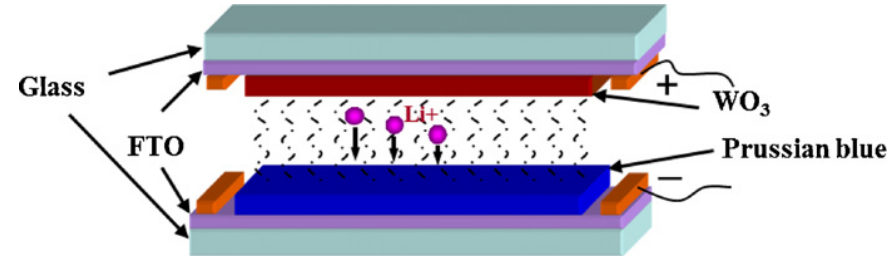

Fig. 1. Schematic of the complementary device.

agent. Then $\mathrm{NaOH}$ ( $1 \mathrm{~mol}$ ) solution was slowly mixed into this solution while rigorously stirring until the $\mathrm{pH}$ value of the solution reached 1.5. For the purpose of comparison, a solution without adding capping agent was also used. The as-prepared solutions were transferred into autoclaves as precursors for hydrothermal treatments. The FTO glasses coated by $\mathrm{WO}_{3}$ seed layers were put into autoclaves and the hydrothermal process was kept at $180^{\circ} \mathrm{C}$ for $18 \mathrm{~h}$.

\subsection{Electrodeposition of $P B$ and preparation of electrochromic device}

The electrodeposition of PB film was carried out by a standard three-electrode system, where a clean FTO served as the working electrode, a platinum sheet as the counter electrode, and a
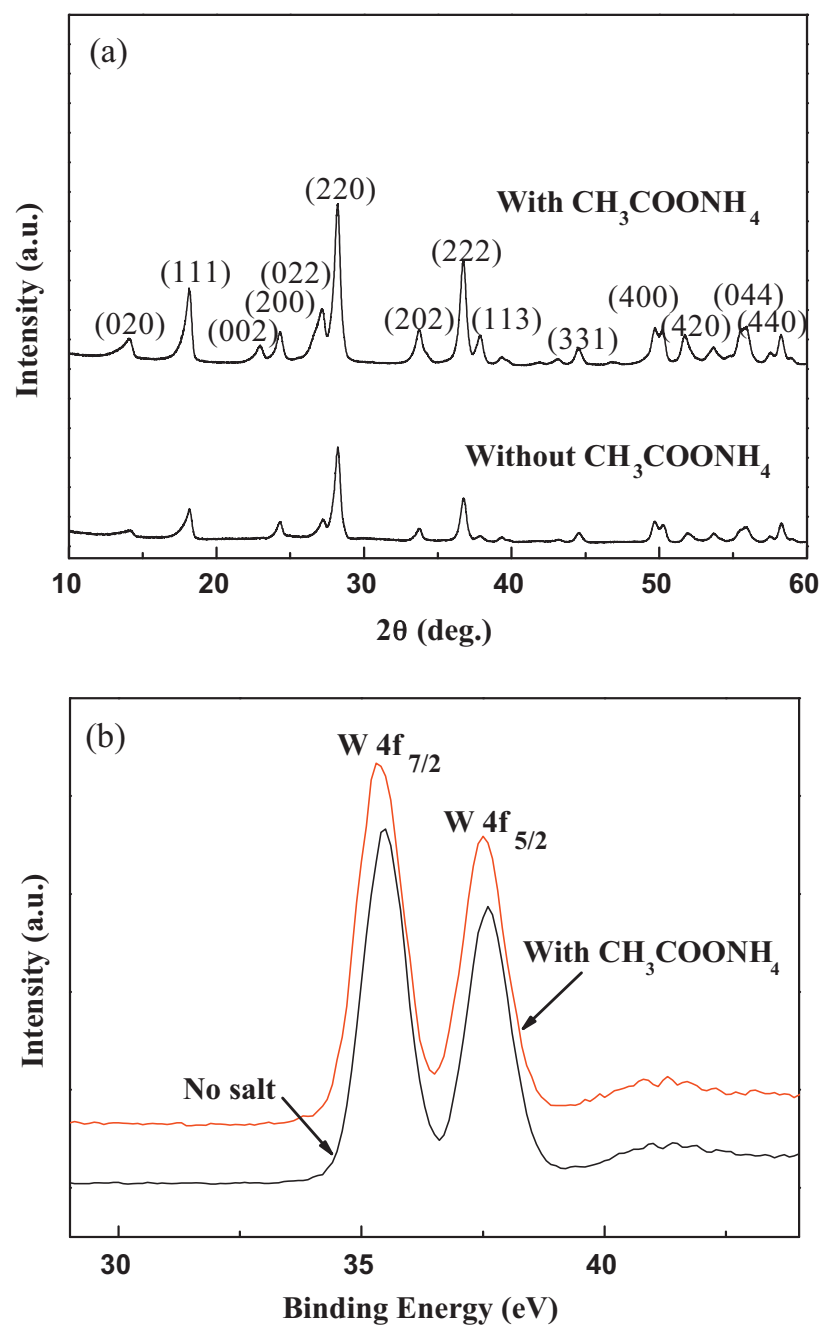

Fig. 2. XRD patterns (a) and (b) tungsten $4 \mathrm{f}$ region XPS spectra of the as-synthesized thin films grown with and without $\mathrm{CH}_{3} \mathrm{COONH}_{4}$. 

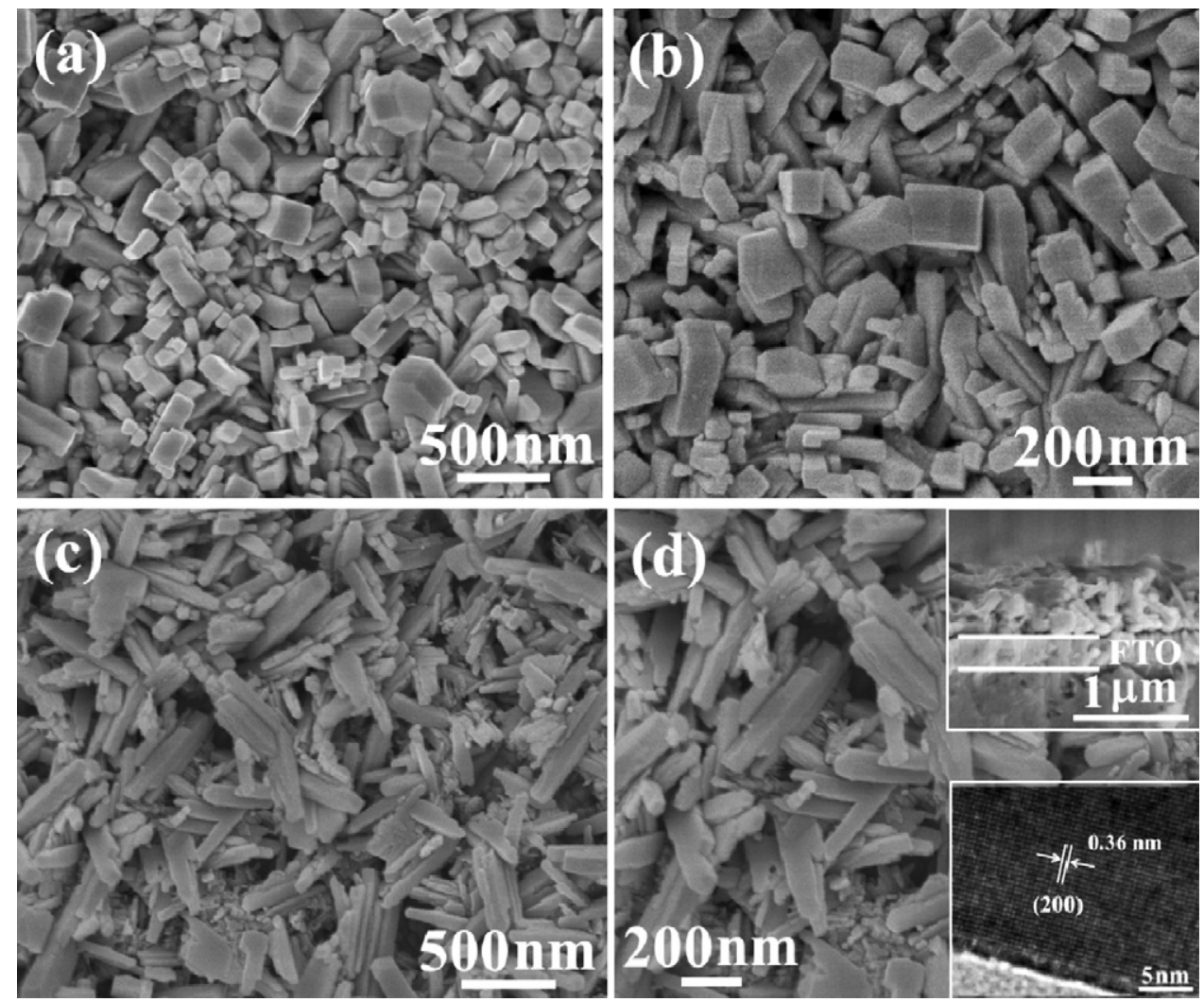

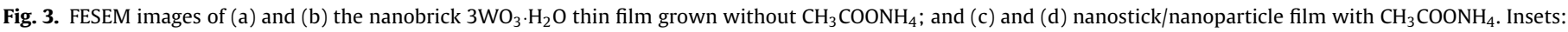
cross-sectional and HRTEM image.

$\mathrm{Ag} / \mathrm{AgCl} /$ sat'd $\mathrm{KCl}$ solution as the reference electrode. The electrodeposition bath of $\mathrm{PB}$ contained $10 \mathrm{mmol} \mathrm{K}_{3} \mathrm{Fe}(\mathrm{CN})_{6}, 10 \mathrm{mmol}$ $\mathrm{FeCl}_{3}$ and $0.1 \mathrm{~mol} \mathrm{KCl}$ and the electrodeposition of $\mathrm{PB}$ thin film was carried out by applying a constant cathodic current density of $50 \mu \mathrm{A} / \mathrm{cm}^{2}$ for $300 \mathrm{~s}$. The thickness of the as-deposited PB film is about $450 \mathrm{~nm}$ (measured by a TENCOR P-10 Surface Profiler). Then the $\mathrm{WO}_{3}$ working electrode and $\mathrm{PB}$ counter electrode were sandwiched together with hot-melt Surlyn spacers. A liquid electrolyte

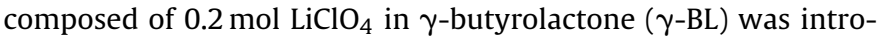
duced between the two electrodes by capillary action. Finally the cell was sealed with epoxy, which is schematically shown in Fig. 1.

\subsection{Characterization}

The phases of the synthesis products were identified by X-ray powder diffraction (XRD, Siemens), using $\mathrm{Cu} \mathrm{K} \alpha_{1}(\lambda=0.15406 \mathrm{~nm})$ radiation. X-ray photoelectron spectroscopy (XPS) data were obtained on a Kratos AXIS spectrometer with monochromatic $\mathrm{Al} \mathrm{K} \alpha(1486.71 \mathrm{eV}) \mathrm{X}$-ray radiation. The morphologies of the asprepared thin films were observed by field emission scanning electron microscope (FESEM, JSM 6340). High-resolution transmission electron microscopy (HRTEM) image was obtained by a JEM-2100 microscope using an accelerating voltage of $200 \mathrm{kV}$. The optical absorbance and transmittance spectra were measured using a UV/V is spectrophotometer (JESCO V670). Electrochemical measurements were performed by a three-electrode system (VersaSTAT 3F Potentiostat/Galvanostat) with $\mathrm{LiClO}_{4}(0.2 \mathrm{~mol})$ in $\gamma$-BL as the electrolyte, Pt sheet as the counter electrode and $\mathrm{Ag} / \mathrm{AgCl} / \mathrm{sat}^{\prime} \mathrm{d} \mathrm{KCl}$ as the reference electrode.

\section{Results and discussion}

\subsection{Structures and morphologies of as-prepared films}

Fig. 2(a) shows the X-ray diffraction (XRD) patterns of the asprepared thin films grown with and without $\mathrm{CH}_{3} \mathrm{COONH}_{4}$. Both films show the same crystalline structure and all peaks can be well indexed to the orthorhombic phase of $3 \mathrm{WO}_{3} \cdot \mathrm{H}_{2} \mathrm{O}$ (JCPDF 87-1203) with the corresponding lattice constants of $a=7.345, b=12.547$ and $c=7.737 \AA$. The sharp peaks indicate the good crystalline quality of

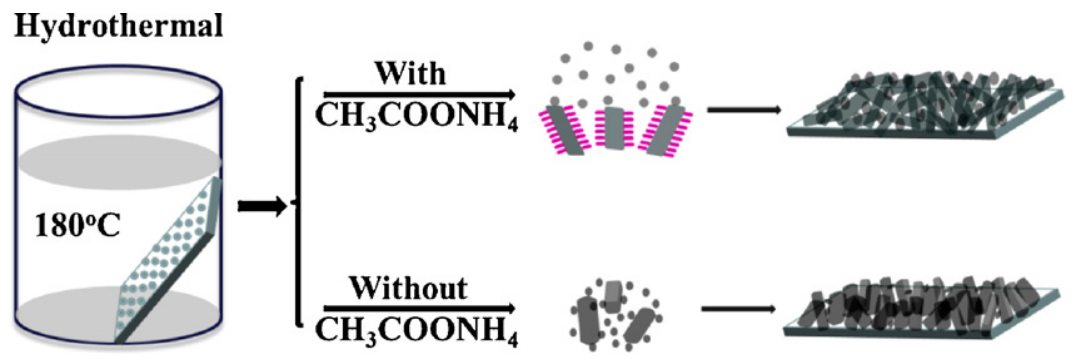

Fig. 4. Schematic illustration of the formation process of the as-grown thin films. 

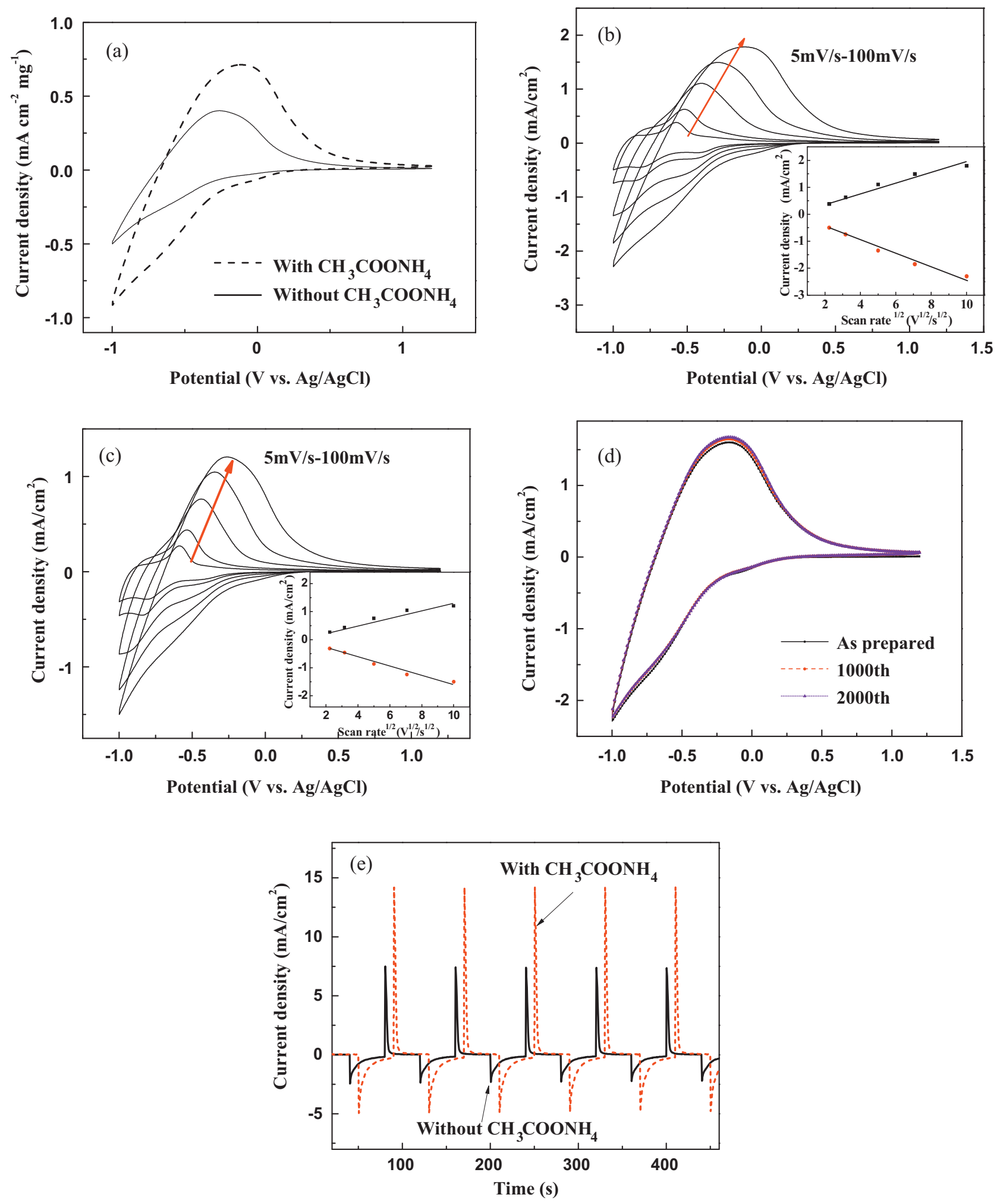

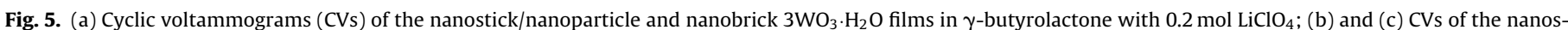

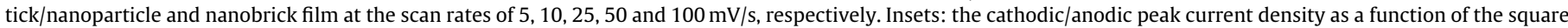

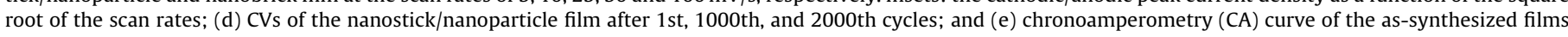
recorded at $\pm 0.5 \mathrm{~V}$ for $40 \mathrm{~s}$.

the as-fabricated films. The electrochromic performance of $\mathrm{WO}_{3}$ is closely related to its crystallinity. Crystalline $\mathrm{WO}_{3}$ has a better stability to endure acidic electrolyte without degradation for a longer cyclic time compared to amorphous one, but at the cost of slower response time and smaller coloration efficiency arising from its smaller specific surface area [31]. By increasing the porosity and precisely controlling the crystal size, crystalline $\mathrm{WO}_{3}$ films with good stability and fast response can simultaneously be achieved. Fig. 2(b) shows the X-ray photoelectron spectroscopy (XPS) data of the as-synthesized films. The binding energies of the samples were 

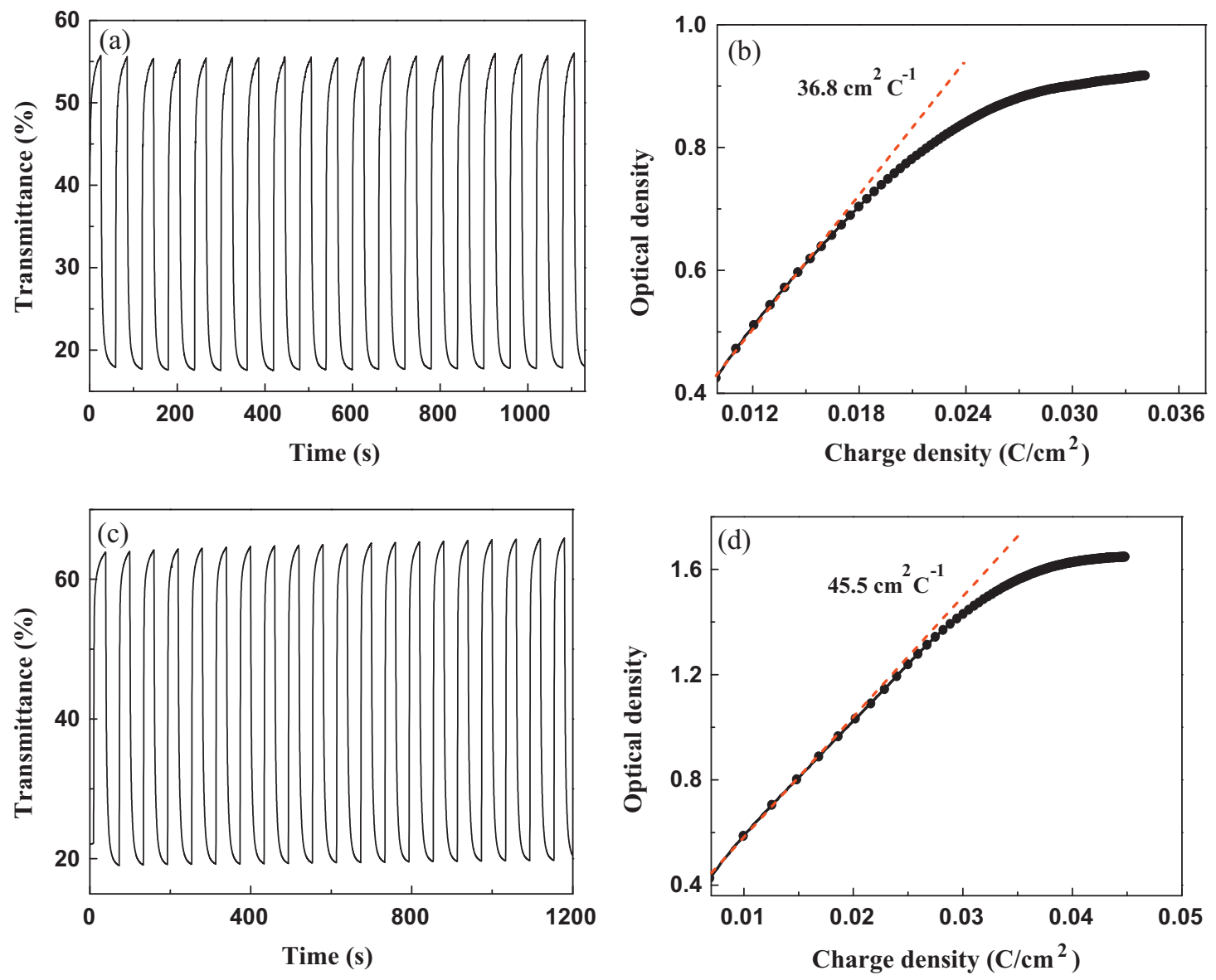

Fig. 6. In situ transmittance response and coloration efficiency at $754 \mathrm{~nm}$ for the nanobrick film (a and b) and the nanostick/nanoparticle film (c and d).

corrected using a value of $284.5 \mathrm{eV}$ for the $\mathrm{C} 1 \mathrm{~s}$ peak of carbon. For both films, two well-resolved peaks at about 35.5 and $37.6 \mathrm{eV}$ in the spectra are attributed to the spin orbit split doublet peaks of $W$ $4 \mathrm{f}_{7 / 2}$ and $\mathrm{W} 4 \mathrm{f}_{5 / 2}$, respectively. These two peaks are well separated without any shoulders, indicating that all $W$ atoms are in the +6 oxidization states.

Fig. 3 shows the morphologies of the as-synthesized films. It can be seen that the film grown without $\mathrm{CH}_{3} \mathrm{COONH}_{4}$ consists of irregular aggregated nanobricks with sizes ranging from tens to hundreds of nanometers (see Fig. 3(a) and (b)), while thin film made up of stacked nanosticks and nanoparticles is obtained by adding $\mathrm{CH}_{3} \mathrm{COONH}_{4}$ as the capping agent (Fig. 3(c) and (d)). The nanosticks with an average length of $\sim 50 \mathrm{~nm}$ are horizontally stacked together, leading to a coarse surface. A lot of small nanoparticles with sizes of tens of nanometers are accumulated underneath these sticks. Clear lattice fringes of the high-resolution transmission electron microscopy (HRTEM) image from a nanostick (inset of Fig. 3(d)) indicate its single crystalline quality. The inset crosssectional image shows that the film with a thickness of $\sim 560 \mathrm{~nm}$ has a good adherence to the substrate. According to the recent report [32], orthorhombic $3 \mathrm{WO}_{3} \cdot \mathrm{H}_{2} \mathrm{O}$ actually contains two type of corner-sharing $\mathrm{WO}_{6}$ octahedras. One type is conducted by a central tungsten atom that is surrounded by six oxygen atoms, while in the second type, two of the oxygen atoms are replaced by a shorter terminal $\mathrm{W}=\mathrm{O}$ bond and longer $\mathrm{W}-(\mathrm{OH})_{2}$ bond, respectively. Finally, the $3 \mathrm{WO}_{3} \cdot \mathrm{H}_{2} \mathrm{O}$ lattice is formed by stacking up layers consisting of these two structural units. Herein, the $\mathrm{CH}_{3} \mathrm{COONH}_{4}$ has a capping effect on the stacking of these two structural units, resulting in the formation of nanosticks. Fig. 4 schematically illustrates the formation process of the films grown with and without $\mathrm{CH}_{3} \mathrm{COONH}_{4}$.

\subsection{Electrochemical and electrochromic properties of the as-prepared $3 \mathrm{WO}_{3} \cdot \mathrm{H}_{2} \mathrm{O}$ films}

Cyclic voltammograms (CVs) were investigated for both films and shown in Fig. 5(a). These CVs were normalized with respect to the geometric area and to the weight of $3 \mathrm{WO}_{3} \cdot \mathrm{H}_{2} \mathrm{O}$ film within that area. During each scan, the films undergo typical reversible color changes from blue to colorless. The recorded current is due to $\mathrm{Li}^{+}$intercalation/deintercalation and electron transfer between $\mathrm{W}^{6+}$ and $\mathrm{W}^{5+}$ according to the following reaction:

$\mathrm{WO}_{3} \cdot 0.33 \mathrm{H}_{2} \mathrm{O}$ (bleach) $+x \mathrm{Li}^{+}+x \mathrm{e}^{-} \leftrightarrow \mathrm{Li}_{x} \mathrm{WO}_{3} \cdot 0.33 \mathrm{H}_{2} \mathrm{O}$ (blue).

The integrated cathodic/anodic current equates to the amount of $\mathrm{Li}^{+}$ intercalation/deintercalation. It can be clearly seen that the nanostick/nanoparticle film grown with $\mathrm{CH}_{3} \mathrm{COONH}_{4}$ shows a higher current density for both intercalation and deintercalation processes over the same time period than the nanobrick one, indicating faster $\mathrm{Li}^{+}$intercalation/deintercalation kinetics. The total cathodic charge for the nanostick/nanoparticle film is about $4.2 \mathrm{mC} \mathrm{cm}^{-2} \mathrm{mg}^{-1}$, compared to only about $2.0 \mathrm{mC} \mathrm{cm}^{-2} \mathrm{mg}^{-1}$ for nanobrick films.

The CVs of nanostick/nanoparticle and nanobrick films recorded between -1.0 and $1.2 \mathrm{~V}$ at various scan speeds are shown in Fig. 5(b) and (c), respectively. It can be seen from Fig. 5(b) that when the scan speed is $5 \mathrm{mV} / \mathrm{s}$, there are two oxidation peaks that appear at about -0.83 and $-0.56 \mathrm{~V}$, and two reduction peaks that appear at -0.45 and $-0.85 \mathrm{~V}$. With the increased scan speed, the first oxidation peaks disappear, while the second peaks get broader and higher, and the peak positions shift to a higher oxidation potential. 


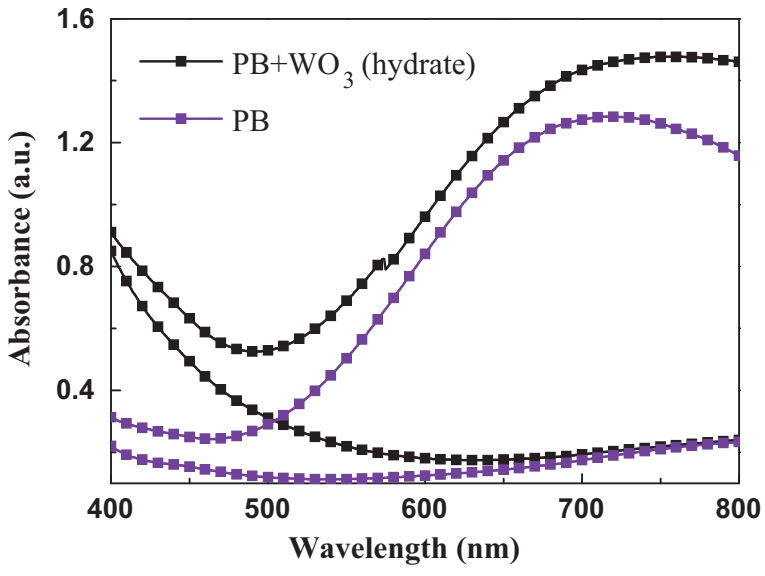

Fig. 7. Optical absorption spectra of a complementary electrochromic device and a single PB layer device at the colored and bleached state under $\pm 0.8 \mathrm{~V}$, respectively.

The reduction peaks show a similar trend. When the second anodic peak current densities are plotted against the square root of scan rates, $v^{1 / 2}$, approximately a linear relationship is obtained (inset of Fig. 5(b)), which signifies a diffusion-controlled process [33]. The effective diffusion coefficient $D$ for the diffusing species $\mathrm{Li}^{+}$can be estimated from the peak current density $\left(j_{p}\right)$ dependence on the
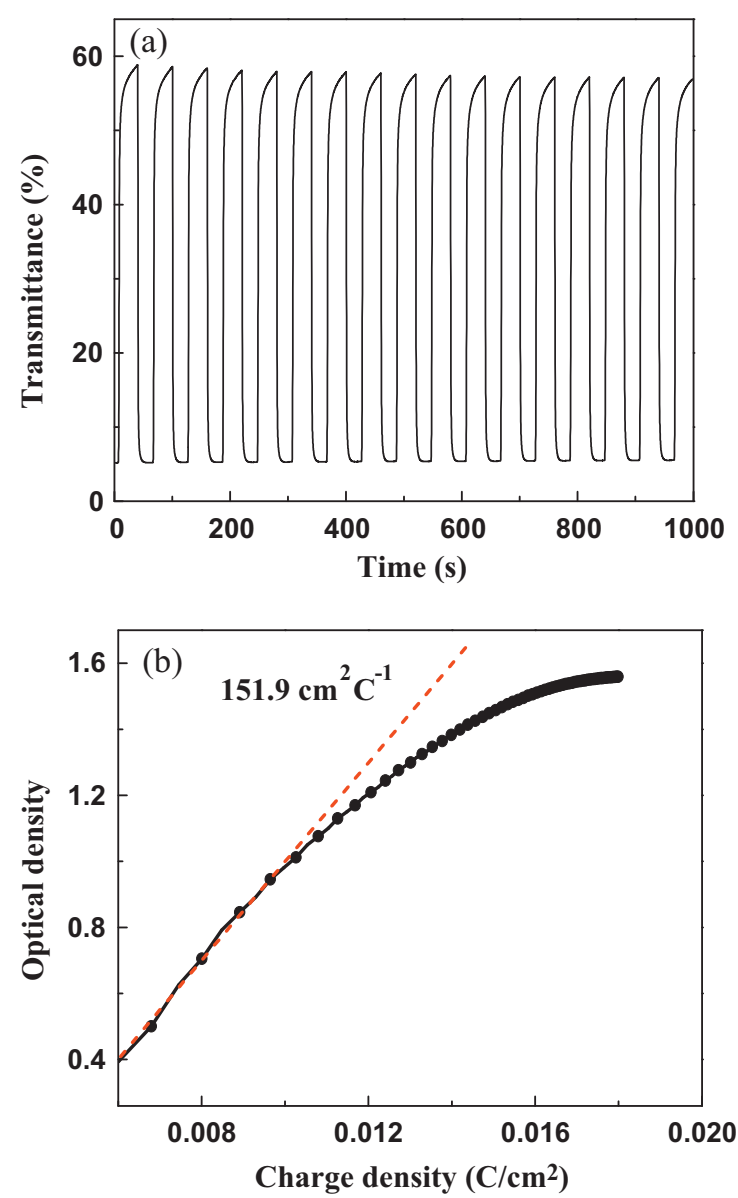

Fig. 8. (a) Switching time characteristics between the colored and bleached states for the complementary electrochromic device measured at $\pm 0.8 \mathrm{~V}$ for $30 \mathrm{~s}$ and (b) optical density variation with respect to the charge density recorded at $754 \mathrm{~nm}$. square root of the potential scan rate $\left(v^{1 / 2}\right)$ assuming a simple solid state diffusion controlled process [34]:

$$
\begin{aligned}
& \frac{\delta i_{p}}{\delta \sqrt{v}}=2.69 \times 10^{5} n^{3 / 2} A C \sqrt{D} \\
& D=0.1382 \times 10^{-10} n^{-3} A^{-2} C^{-2}\left(\frac{\delta i_{p}}{\delta \sqrt{v}}\right)^{2}
\end{aligned}
$$

where $n$ is the number of electrons transferred in unit reaction, $A$ is the effective geometric surface area of the $3 \mathrm{WO}_{3} \cdot \mathrm{H}_{2} \mathrm{O}$ electrode, and $C$ is the concentration of the diffusion species $\left(\mathrm{Li}^{+}\right)$. The effective diffusion coefficients $D_{\mathrm{Li}^{+}}$have been calculated from Eq. (3) to be $2.19 \times 10^{-11}$ and $1.39 \times 10^{-11} \mathrm{~cm}^{2} / \mathrm{s}$ for the intercalation and deintercalation process, respectively, comparable to the reported values [35]. Fig. 5(c) shows the CVs of the nanobrick film recorded at different scan rates, showing a similar profile but smaller current density. The calculated diffusion coefficients $D_{\mathrm{Li}^{+}}$are $9.60 \times 10^{-12}$ and $6.101 \times 10^{-12} \mathrm{~cm}^{2} / \mathrm{s}$ for the intercalation process and deintercalation process, respectively, which are smaller than those of the nanostick/nanoparticle film. The faster ion diffusion kinetics of the nanostick/nanoparticle film arises from its much rougher surface, which increases its surface area and reduces the ions diffusion path length. The cyclic stability of the nanostick/nanoparticle film was also measured for the 1st, 1000th, and 2000th cycle at room temperature and the results are shown in Fig. 5(d). The current density increases slightly within 2000 cycles, without a clear change in the shape of CV curve, indicating excellent cyclic stability of the film, which is similar to the reported crystalline $\mathrm{WO}_{3}$ nanoparticles [12]. Chronoamperometry (CA) data were recorded for both films with the potential being stepped from $-0.5 \mathrm{~V}$ to $+0.5 \mathrm{~V}$ for $40 \mathrm{~s}$, as shown in Fig. $5(\mathrm{e})$. During each cycle, the $3 \mathrm{WO}_{3} \cdot \mathrm{H}_{2} \mathrm{O}$ films change from bleached state to colored state reversibly. For both films, the peak current density of bleaching is much higher than that of coloration, and the current density during bleaching decays faster than coloration. This characteristic is typical for $\mathrm{WO}_{3}$ with small ion intercalation/deintercalation [20]. The higher bleaching current arises from the good conductivity of tungsten bronze $\left(\mathrm{Li}_{x} \mathrm{WO}_{3}\right)$, and the rapid current decay is due to the conductor $\left(\mathrm{Li}_{x} \mathrm{WO}_{3}\right)$ to-semiconductor $\left(\mathrm{WO}_{3}\right)$ transition, while the coloring kinetics is always slower than the bleaching one for $\mathrm{WO}_{3}$ films owing to the higher resistance during $\mathrm{WO}_{3}$ to $\mathrm{Li}_{x} \mathrm{WO}_{3}$ transition. Moreover, the peak current densities of coloration/bleaching ( -4.9 and $14.1 \mathrm{~mA} / \mathrm{cm}^{2}$ ) of the nanostick/nanoparticle film are higher than those $\left(-2.4\right.$ and $\left.7.5 \mathrm{~mA} / \mathrm{cm}^{2}\right)$ of the nanobrick film. The response time (defined as $70 \%$ decrease of current density) for coloration $\left(t_{\mathrm{c}}\right)$ and bleaching $\left(t_{\mathrm{b}}\right)$ are calculated from current-time transient data from Fig. 5(e). The nanostick/nanoparticle film shows faster coloration/bleaching responses $\left(t_{\mathrm{c}} \sim 7.0 \mathrm{~s}\right.$ and $\left.t_{\mathrm{b}} \sim 3.0 \mathrm{~s}\right)$ than those $\left(t_{\mathrm{c}} \sim 9.0 \mathrm{~s}\right.$ and $\left.t_{\mathrm{b}} \sim 3.5 \mathrm{~s}\right)$ of the nanobrick film, in well agreement with the results in Fig. 5(a-c). The fast responses for both films are comparable to the spray-pyrolysis deposited amorphous $\mathrm{WO}_{3}$ film [36].

The in situ transmittance responses of the nanostick/nanoparticle and nanobrick film for a $90 \%$ transmittance change were also investigated at $754 \mathrm{~nm}$ by a $\pm 0.8 \mathrm{~V}$ bias (see Fig. 6(a) and (c)). For the nanostick/nanoparticle film, the coloration time $t_{\mathrm{c}}$ is found to be $7.9 \mathrm{~s}$, and the bleaching time $t_{\mathrm{b}}$ is $4.8 \mathrm{~s}$. However, for the nanobrick film, the coloration time $t_{\mathrm{c}}$ is found to be $7.3 \mathrm{~s}$, and the bleaching time $t_{\mathrm{b}}$ is $7.1 \mathrm{~s}$. The bleaching speed of the nanostick/nanoparticle film is much faster than the nanobrick film, but the coloration speed is a little slower. It is worth to mention that a larger optical modulation of $\sim 45 \%$ of the nanostick/nanoparticle film is achieved, compared to that only $38 \%$ of the nanobrick film. Coloration efficiency (CE) values of both films were also studied and shown in Fig. 6(b) and (d), respectively. The CE is extracted as the slope of the line fits to the 

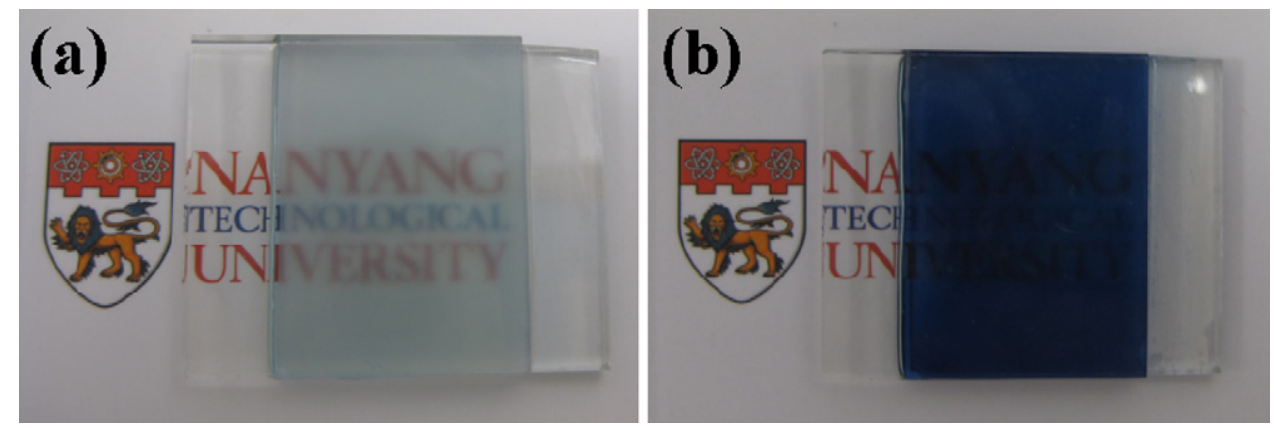

Fig. 9. Photographs of a complementary electrochromic device at the bleached state (a) and (b) the colored state under $\pm 0.8 \mathrm{~V}$, respectively.

linear region of the curve. It can be seen that the calculated $\mathrm{CE}$ of the nanostick/nanoparticle film is $45.5 \mathrm{~cm}^{2} / \mathrm{C}$, larger than that of the nanobrick film $\left(36.8 \mathrm{~cm}^{2} / \mathrm{C}\right)$. The improved electrochromic performance of the nanostick/nanoparticle film is due to its large surface area.

\subsection{Optical and electrochromic properties of the complementary device}

To further improve the optical contrast, coloration efficiency and switching stability, the nanostick/nanoparticle film is incorporated in an electrochromic device with an anodically colored PB film as a complementary electrochromic layer. The morphology and CV curve of the as-deposited PB film were also investigated and shown in Figs. S1 and S2, respectively (see supplementary information). Fig. 7 shows optical absorption spectra of the complementary electrochromic device and a single PB layer device at the bleached and colored state under $\mathrm{a} \pm 0.8 \mathrm{~V}$ bias. Compared with the single PB layer device, the complementary device shows a larger optical modulation above $410 \mathrm{~nm}$, especially in the near IR region, indicating a higher color contrast and larger heat regulation. Moreover, the complementary device depicts a higher absorption in the near UV region at both colored and bleached states due to the absorption of $3 \mathrm{WO}_{3} \cdot \mathrm{H}_{2} \mathrm{O}$ films. The above result is highly desired in smart window applications since more heat can be prohibited from entering the interior buildings, resulting in a reduction of cooling loads.

Fig. 8(a) shows the in situ coloration/bleaching transmittance response of the complementary device measured at $754 \mathrm{~nm}$. The maximum transmittance modulation $(\Delta T)$ of coloration/bleaching was found to be about $54 \%$ after applying a $\pm 0.8 \mathrm{~V}$ voltage for $30 \mathrm{~s}$, agreeing well with the absorbance spectra shown in Fig. 7. Obvious color changes can be observed during the switching. The coloration and bleaching time extracted as $90 \%$ transmittance changes are found to be 1.3 and $5.7 \mathrm{~s}$, respectively. The switching responses of the complementary device for both the coloration and bleaching processes are much faster than those reported values [30]. For this complementary electrochromic device, limitations of switching response are mainly due to $3 \mathrm{WO}_{3} \cdot \mathrm{H}_{2} \mathrm{O}$ electrode. The fast coloration/bleaching kinetics may be attributed to the large active specific area of the rough surface, which facilitates the ions intercalation/deintercalation by reducing their diffusion lengths. $\mathrm{CE}$ of the complementary cell was also investigated at its peak absorbance $(\lambda=754 \mathrm{~nm})$ and shown in Fig. $8(\mathrm{~b})$. The calculated $C E$ value is $151.9 \mathrm{~cm}^{2} / C$, comparable to that of the reported $\mathrm{WO}_{3} \| \mathrm{PB}$ complementary device [30]. And the $\mathrm{CE}$ of the complementary device is improved by about $234 \%$ compared with a single $3 \mathrm{WO}_{3} \cdot \mathrm{H}_{2} \mathrm{O}$ electrochromic layer $\left(\mathrm{CE}=45.5 \mathrm{~cm}^{2} / \mathrm{C}\right)$. Photographs of the complementary device are shown in Fig. 9, depicting a high contrast between the bleached and colored states, which leads to the obvious transparence changes. The device shows promising applications in energy-saving smart windows.

\section{Conclusions}

In summary, uniform and well-adhesive $3 \mathrm{WO}_{3} \cdot \mathrm{H}_{2} \mathrm{O}$ films consisted of nanosticks/nanoparticles were synthesized via a facile and template-free hydrothermal method by adding $\mathrm{CH}_{3} \mathrm{COONH}_{4}$ as the capping agent. Thin films composed of aggregated nanobricks were obtained without $\mathrm{CH}_{3} \mathrm{COONH}_{4}$. The nanostick/nanoparticle film depicts faster charge transfer and greater coloration efficiency $\left(45.5 \mathrm{~cm}^{2} / \mathrm{C}\right)$ than the nanobrick film $\left(36.8 \mathrm{~cm}^{2} / \mathrm{C}\right)$. A complementary electrochromic device based on the nanostick/nanoparticle $3 \mathrm{WO}_{3} \cdot \mathrm{H}_{2} \mathrm{O}$ film and $\mathrm{PB}$ film was fabricated and demonstrates larger optical contrast ( $54 \%$ at $754 \mathrm{~nm}$ ), faster switching response $\left(t_{\mathrm{b}}=1.3 \mathrm{~s}\right.$ and $\left.t_{\mathrm{c}}=5.7 \mathrm{~s}\right)$ and greater coloration efficiency $\left(151.9 \mathrm{~cm}^{2} / \mathrm{C}\right)$ than a single $3 \mathrm{WO}_{3} \cdot \mathrm{H}_{2} \mathrm{O}$ film device. The complementary device holds great promise for potential applications in energy-saving smart windows.

\section{Acknowledgments}

The authors would like to thank the financial support from the Science and Engineering Research Council, Agency for Science, Technology and Research (A*STAR) of Singapore (project Nos. 0921010057 and 092151 0088), Singapore NRF-RF-2009-09, and National Natural Science Foundation of China (NSFC) (project Nos. 61006037 and 61076015).

\section{Appendix A. Supplementary data}

Supplementary data associated with this article can be found, in the online version, at doi:10.1016/j.electacta.2011.12.069.

\section{References}

[1] C.G. Granqvist, P.C. Lansaker, N.R. Mlyuka, G.A. Niklasson, E. Avendano, Sol. Energy Mater. Sol. Cells 93 (2009) 2032.

[2] R.J. Mortimer, Chem. Soc. Rev. 26 (1997) 147.

[3] C.R. Granqvist, Nat. Mater. 5 (2006) 89.

[4] C.M. Lampert, Sol. Energy Mater. 11 (1984) 1

[5] G.A. Niklasson, C.G. Granqvist, J. Mater. Chem. 17 (2007) 127.

[6] C.G. Granqvist, A. Azens, A. Hjelm, L. Kullman, G.A. Niklasson, D. Ronnow, M.S Mattsson, M. Veszelei, G. Vaivars, Sol. Energy 63 (1998) 199.

[7] R.J. Mortimer, A.L. Dyer, J.R. Reynolds, Displays 27 (2006) 2.

[8] P. Bonhote, E. Gogniat, F. Campus, L. Walder, M. Gratzel, Displays 20 (1999) 137

[9] D.R. Rosseinsky, R.J. Mortimer, Adv. Mater. 13 (2001) 783.

[10] R. Baetens, B.P. Jelle, A. Gustavsen, Sol. Energy Mater. Sol. Cells 94 (2010) 87.

[11] C.G. Granqvist, Sol. Energy Mater. Sol. Cells 60 (2000) 201.

[12] S.H. Lee, R. Deshpande, P.A. Parilla, K.M. Jones, B. To, A.H. Mahan, A.C. Dillon, Adv. Mater. 18 (2006) 763.

[13] H.D. Zheng, J.Z. Ou, M.S. Strano, R.B. Kaner, A. Mitchell, K. Kalantar-Zadeh, Adv. Funct. Mater. 21 (2011) 2175.

[14] J.M. O-Rueda de León, D.R. Acosta, U. Pal, L. Castañeda, Electrochim. Acta 56 (2011) 2599.

[15] S. Hashimoto, H. Matsuoka, J. Electrochem. Soc. 138 (1991) 2403. 
[16] H.G. Choi, Y.H. Jung, D.K. Kim, J. Am. Ceram. Soc. 88 (2005) 1684.

[17] K.Q. Hong, M.H. Xie, H.S. Wu, Nanotechnology 17 (2006) 4830.

[18] D.Z. Guo, K. Yu-Zhang, A. Gloter, G.M. Zhang, Z.Q. Xue, J. Mater. Res. 19 (2004) 3665.

[19] J.M. Wang, E. Khoo, P.S. Lee, J. Ma, J. Phys. Chem. C 112 (2008) 14306

[20] H. Wang, X. Quan, Y. Zhang, S. Chen, Nanotechnology 19 (2008) 065704

[21] R.A. Batchelor, M.S. Burdis, J.R. Siddle, J. Electrochem. Soc. 143 (1996) 1050

[22] S.H. Baeck, K.S. Choi, T.F. Jaramillo, G.D. Stucky, E.W. McFarland, Adv. Mater. 15 (2003) 1269.

[23] S. Balaji, Y. Djaoued, A.S. Albert, R. Bruning, N. Beaudoin, J. Robichaud, J. Mater. Chem. 21 (2011) 3940.

[24] Z.H.Jiao, X.W. Sun, J.M. Wang, L. Ke, H.V. Demir, J. Phys. D: Appl. Phys. 43 (2010) 285501.

[25] J. Zhang, X.L. Wang, X.H. Xia, C.D. Gu, J.P. Tu, Sol. Energy Mater. Sol. Cells 95 (2011) 2107.

[26] Z.J. Gu, T.Y.Zhai, B.F. Gao, X.H. Sheng, Y.B. Wang, H.B. Fu, Y. Ma, J.N. Yao, J. Phys. Chem. B 110 (2006) 23829 .
[27] J. Zhang, J.P. Tu, X.H. Xia, X.L. Wang, C.D. Gu, J. Mater. Chem. 21 (2011) 5492.

[28] J. Zhang, J.P. Tu, X.H. Xia, Y. Qiao, Y. Lu, Sol. Energy Mater. Sol. Cells 93 (2009) 1840 .

[29] H. Huang, J. Tian, W.K. Zhang, Y.P. Gan, X.Y. Tao, X.H. Xia, J.P. Tu, Electrochim. Acta 56 (2011) 4281.

[30] A. Kraft, M. Rottmann, Sol. Energy Mater. Sol. Cells 93 (2009) 2088.

[31] M. Deepa, T.K. Saxena, D.P. Singh, K.N. Sood, S.A. Agnihotry, Electrochim. Acta $51(2006) 1974$.

[32] L. Zhou, J. Zou, M.M. Yu, P. Lu, J. Wei, Y.Q. Qian, Y.H. Wang, C.Z. Yu, Cryst. Growth Des. 8 (2008) 3993.

[33] A.J. Bard, L.R. Faulkner, Electrochemical Methods, Fundamentals and Applications, Wiley, New York, 2001.

[34] I. Shiyanovskaya, M. Hepel, E. Tewksburry, J. New Mater. Electrochem. Syst. 3 (2000) 241.

[35] S.R. Bathe, P.S. Patil, Smart Mater. Struct. 18 (2009) 025004

[36] S.R. Bathe, P.S. Patil, Sol. Energy Mater. Sol. Cells 91 (2007) 1097. 